\title{
Effect of nasal or oral breathing route on upper airway resistance during sleep
}

\author{
M.F. Fitzpatrick*, H. McLean*, A.M. Urton*, A. Tan*, D. O'Donnell*, H.S. Driver
}

Effect of nasal or oral breathing route on upper airway resistance during sleep. M.F. Fitzpatrick, H. McLean, A.M. Urton, A. Tan, D. O'Donnell, H.S. Driver. (C)ERS Journals Ltd 2003.

ABSTRACT: Healthy subjects with normal nasal resistance breathe almost exclusively through the nose during sleep. This study tested the hypothesis that a mechanical advantage might explain this preponderance of nasal over oral breathing during sleep.

A randomised, single-blind, crossover design was used to compare upper airway resistance during sleep in the nasal and oral breathing conditions in 12 (seven male) healthy subjects with normal nasal resistance, aged $30 \pm 4$ (mean \pm SEM) yrs, and with a body mass index of $23 \pm 1 \mathrm{~kg} \cdot \mathrm{m}^{2}$.

During wakefulness, upper airway resistance was similar between the oral and nasal breathing routes. However, during sleep (supine, stage two) upper airway resistance was much higher while breathing orally (median $12.4 \mathrm{cmH}_{2} \mathrm{O} \cdot \mathrm{L}^{-1} \cdot \mathrm{s}^{-1}$, range 4.5-40.2) than nasally $\left(5.2 \mathrm{cmH}_{2} \mathrm{O} \cdot \mathrm{L}^{-1} \cdot \mathrm{s}^{-\mathrm{T}}, 1.7-10.8\right)$. In addition, obstructive (but not central) apnoeas and hypopnoeas were profoundly more frequent when breathing orally (apnoeahypopnoea index $43 \pm 6$ ) than nasally $(1.5 \pm 0.5)$.

Upper airway resistance during sleep and the propensity to obstructive sleep apnoea are significantly lower while breathing nasally rather than orally. This mechanical advantage may explain the preponderance of nasal breathing during sleep in normal subjects.

Eur Respir J 2003; 22: 827-832.
*Depts of Medicine and ${ }^{\#}$ Otolaryngology, Queen's University, and 'Kingston General Hospital, Kingston, Ontario, Canada.

Correspondence: M. Fitzpatrick, Division of Respiratory and Critical Care Medicine, Queen's University, 102 Stuart Street, Kingston, Ontario, K7L 2V6, Canada.

Fax: 16135491459

E-mail: mf19@post.queensu.ca

Keywords: Breathing route mouth breathing

sleep apnoea

upper airway resistance

Received: April 302003

Accepted after revision: June 162003

This study was funded by grants from the William M. Spear Foundation, Queen's University and the Physicians' Service Incorporated Foundation, Ontario.
In a recent publication the authors described, for the first time, partitioning of inhaled ventilation between the nose and mouth during sleep in healthy subjects with normal nasal resistance [1]. The main finding of the latter study was that the oral fraction of inhaled ventilation during sleep was very small, averaging only $4 \%$ for the group of 10 subjects, and several subjects did not breathe through their mouth at all during sleep. Furthermore, the inhaled oral fraction did not change significantly between different non-rapid eye movement sleep stages or between rapid eye movement (REM) and non-REM sleep.

The physiological explanation for the marked predominance of nasal ventilation over oral ventilation during sleep in normal subjects is unknown. Since total airway resistance while awake and breathing through the mouth is typically $2-4 \mathrm{cmH}_{2} \mathrm{O} \cdot \mathrm{L}^{-1} \cdot \mathrm{s}^{-1}[2]$ and the normal nasal resistance alone is of similar magnitude [3], it is not intuitively obvious why healthy subjects should choose to breathe almost exclusively through the nasal route during sleep. Specifically, there are no published measurements describing the effect of oral versus nasal breathing on upper airway resistance during sleep.

It is important to understand the influence of the breathing route (oral or nasal) on upper airway resistance during sleep from the perspective of understanding normal respiratory physiology during sleep, but this information may also provide an insight into the relationship between the breathing route and upper airway obstruction during sleep. The authors hypothesised that the observed preponderance of nasal over oral ventilation in normal subjects during sleep would reflect a mechanical advantage of the nasal breathing route. To test this hypothesis, the authors compared upper airway resistance during nasal breathing and during oral breathing in healthy sleeping subjects with normal nasal resistance.

\section{Methods}

\section{Study design}

A randomised, single blind, crossover study was conducted to compare upper airway resistance during sleep when nose breathing with that when mouth breathing. Subjects underwent a single overnight polysomnogram at Kingston General Hospital Sleep Laboratory, Ontario. The night was divided into two parts, oral breathing and nasal breathing, the order being randomised between subjects.

Respondents to a newspaper advertisement were screened by telephone interview to exclude those with a history of regular loud snoring, nasal obstruction, sleep complaints, systemic illnesses and medication use. Twelve subjects (seven male, five female) were selected for further study, aged $30 \pm 4$ (mean \pm SEM) yrs (range 20-64 yrs), with a body mass index of $22.7 \pm 0.7 \mathrm{~kg} \cdot \mathrm{m}^{-2}\left(19.4-27.4 \mathrm{~kg} \cdot \mathrm{m}^{-2}\right)$. On the evening of the overnight sleep study, subjects underwent spirometry and completed an Epworth Sleepiness Scale score (table 1). Nasal resistance was measured both seated and supine by posterior active rhinometry, as per the authors usual protocol [1], $2 \mathrm{~h}$ prior to the start of the overnight sleep study. Sleep recordings were conducted from 24:00 until 7:00 h, or until the 
subject requested that the study be terminated. Respiratory events were scored using standard criteria [4].

Oral and nasal ventilation were simultaneously measured using a mask (7900 series, no. 7920, adult large; Hans Rudolph, Kansas City, MO, USA) with independent nasal and oral compartments, which was sealed to the skin using spirit gum (Graftobian, WI, USA). The dead space of the oronasal mask was $31.3 \mathrm{~mL}$. The mask was customised with light transparent polythene, to replace the lower portion of the oral compartment that would normally rest on the chin. The patient was asked to fully open the mouth and, with the mouth open, the free edge of the polythene was affixed to the chin and facial skin using spirit gum and tape (fig. 1). An identical pneumotach (3700 series; Hans Rudolph) was attached to the oral and nasal ports of the facemask. Each pneumotach was attached to a separate research pneumotach system (HSS100HR; Hans Rudolph) that provided a digital output $(40 \mathrm{~Hz}$ sampling frequency) of airflow rate and breath-by-breath tidal volume and the signals were interfaced with the computerised polysomnographic montage (Sandman; Mallinckrodt, Ottawa, Canada). The dead space of each pneumotach was $13.87 \mathrm{~mL}$. During the nasal breathing condition, the breathing port of the oral pneumotach was sealed with a purpose-made airtight plastic plug, while the nasal pneumotach was left open, and vice versa for the oral breathing condition. The timing of the switch from one breathing mode to the other was made on the basis of either $2 \mathrm{~h}$ of sleep being obtained in that breathing mode or $4 \mathrm{~h}$ of recording elapsed. Air leaks and communication between the oral and nasal compartments of the facemask were meticulously excluded by regular testing throughout each test night, as per the authors normal routine [1]. Subjects wore a soft neck collar to stabilise neck position during sleep, as neck position can influence upper airway resistance [5-7].

Supraglottic pressure was measured continuously during each study using either a $6 \mathrm{~F}$ infant feeding tube with $0.5 \mathrm{~L} \cdot \mathrm{min}^{-1}$ bias flow attached, or a custom-made $6 \mathrm{~F}$ balloon catheter (Ackrad Laboratories, Cranford, NJ, USA) with a $1 \mathrm{~cm}$ long supraglottic balloon, inserted via the naris. The pharynx was lightly anaesthetised with either two or three sprays of $1 \%$ xylocaine, and the catheter was introduced through one nostril and advanced under laryngoscopic guidance until the tip/balloon lay $\sim 0.5 \mathrm{~cm}$ above the aryepiglottic folds. The tubing from the proximal pressure port of each pneumotach was split using a $\mathrm{Y}$ connector to provide

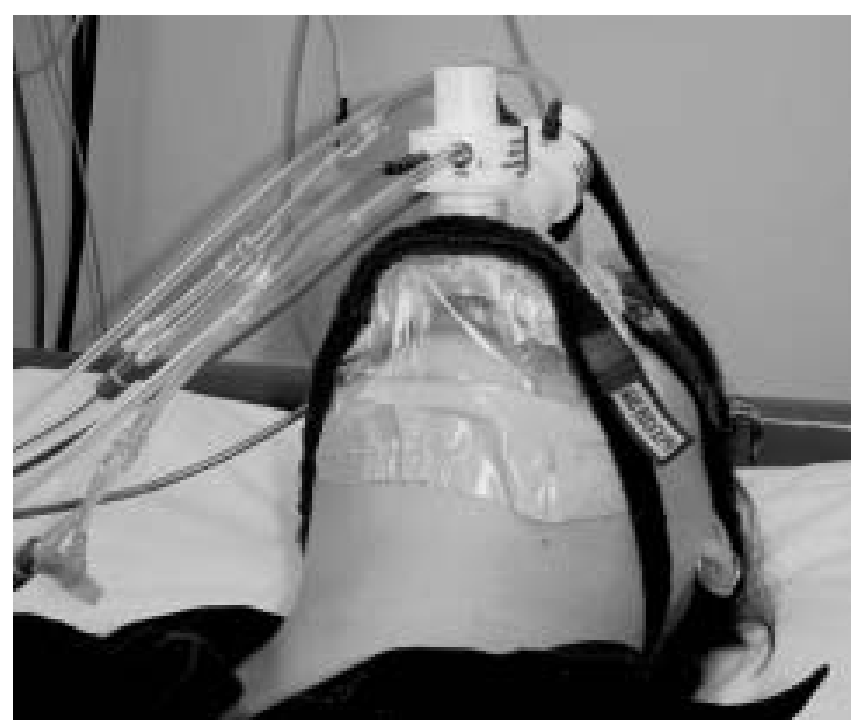

Fig. 1.- Patient wearing oronasal mask. mask pressure, which was measured by a separate pressure transducer (Ultima; Braebon, Ontario, Canada), and pressure and flow signals, which were fed to the research pneumotach system. Upper airway resistance was calculated as the change in differential pressure between the mask and supraglottic catheter tip over the linear part of the inspiratory flow curve [8], divided by the change in flow rate, and then standardised for a flow rate of $0.3 \mathrm{~L} \cdot \mathrm{s}^{-1}$ [3]. The research assistant scoring the sleep studies was blinded to the oral or nasal breathing condition by viewing a scoring montage with only a single airflow signal.

The sleep recording montage included, in addition to nasal and oral airflow and tidal volume signals, and continuous supraglottic and mask pressure signals, four electroencephalogram channels (C4-A1, C3-A2, O2-A1, O1-A2), two electrooculogram channels (ROC-A1, LOC-A2), submental electromyogram (EMG), intercostal (diaphragmatic surface) EMG, electrocardiogram, chest and abdominal movement (piezo bands), finger pulse oximetry, bilateral anterior tibialis EMG and a vibration snore sensor. Each subject was monitored continuously by infrared video camera to document body position changes.

Epochs of sleep of $30 \mathrm{~s}$ duration were standardised for sleep stage and position during the nasal and oral breathing parts of the study, and tabulated. A random number generator was used to select 50 random breaths for upper airway resistance analysis during each part (oral and nasal) of the study. Breaths that occurred during apnoeic events were excluded $a$ priori as upper airway resistance would be infinite in that circumstance.

\section{Statistical analysis}

An analysis of variance was conducted on the data and the residuals were plotted to assess compliance with normality and constant variance. Data not conforming to the normal distribution were analysed using Wilcoxon signed ranks testing, whereas the normally distributed data were analysed using paired t-testing. Bonferroni correction for multiple comparisons was applied when appropriate.

\section{Results}

Nasal resistance values for each individual were within normal limits in both seated and supine positions (seated position: $1.77 \pm 0.2($ mean $\pm \mathrm{SEM}) \mathrm{cmH}_{2} \mathrm{O} \cdot \mathrm{L}^{-1} \cdot \mathrm{s}^{-1}$, range $1.00-2.69$; supine position: $\left.2.05 \pm 0.3 \mathrm{cmH} \mathrm{C}_{2} \mathrm{O} \cdot \mathrm{L}^{-1} \cdot \mathrm{s}^{-1}, 1.10-4.51\right)$. Total sleep time for subjects while nasally breathing was $97.5 \pm 6 \mathrm{~min}$, and while orally breathing was $69.4 \pm 9$ min.

During wakefulness the upper airway resistance values during oral $\left(1.7 \mathrm{cmH}_{2} \mathrm{O} \cdot \mathrm{L}^{-1} \cdot \mathrm{s}^{-1}, 0.8-3.8\right)$ and nasal $\left(2.4 \mathrm{cmH}_{2} \mathrm{O} \cdot \mathrm{L}^{-1} \cdot \mathrm{s}^{-1}\right.$, $1.0-6.1)$ breathing were similar in both lateral $(\mathrm{p}=0.29)$ and supine $(\mathrm{p}=0.16)$ positions. While asleep, the upper airway resistance during nasal ventilation $\left(5.65 \mathrm{cmH}_{2} \mathrm{O} \cdot \mathrm{L}^{-1} \cdot \mathrm{s}^{-1}, 1.8-20.4\right)$ was significantly lower than that during oral ventilation (14.9 $\mathrm{cmH}_{2} \mathrm{O} \cdot \mathrm{L}^{-1} \cdot \mathrm{s}^{-1}, 5.8-30.4 ; \mathrm{p}=0.005$ (fig. 2)). No significant difference was found between the two test orders (nasaloral or oral-nasal) in the airway resistance during sleep for either the nasal $(\mathrm{p}=0.47)$ or oral $(\mathrm{p}=0.68)$ breathing conditions. The percentage of total sleep time spent supine was not significantly different between the nasal $(96 \%, 0-100 \%)$ and oral $(91 \%, 0-100 \% ; \mathrm{p}=0.12)$ breathing conditions. In addition, when upper airway resistance was standardised for sleep stage and position (eight subjects had supine stage two sleep) it was still significantly greater during oral ventilation (median $\left.12.4 \mathrm{cmH}_{2} \mathrm{O} \cdot \mathrm{L}^{-1} \cdot \mathrm{s}^{-1}, 4.5-40.2\right)$ than during nasal ventilation 


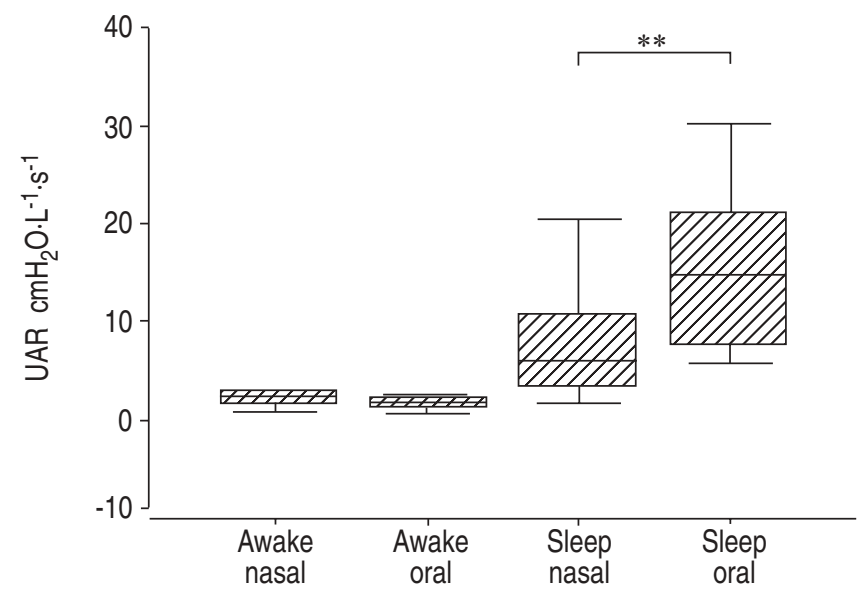

Fig. 2. - Upper airway resistance (UAR) during oral and nasal breathing while awake and asleep. Data are presented as mean \pm SEM. **: $\mathrm{p}<0.01$. $\mathrm{n}=10$ for each category.

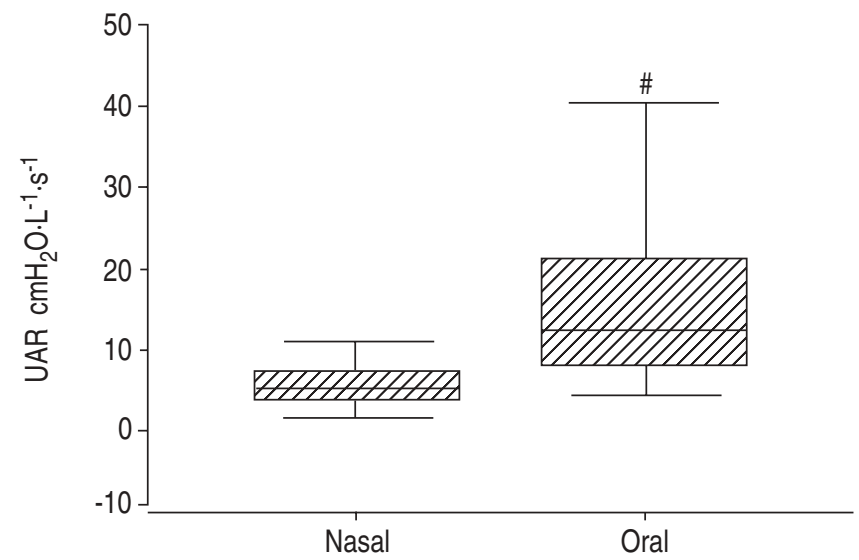

Fig. 3. - Effect of breathing route on upper airway resistance (UAR) during supine stage two sleep. Data are presented as mean \pm SEM. ${ }^{\#}$ : $\mathrm{p}=0.012$.

(5.2 $\mathrm{cmH}_{2} \mathrm{O} \cdot \mathrm{L}^{-1} \cdot \mathrm{s}^{-1}, 1.7-10.8 ; \mathrm{p}=0.012$ (fig. 3)). In response to the increased resistive load in the mouth breathing condition while asleep, the proportion of the respiratory duty cycle taken up by inspiration (time taken to inspire during a single breath/total duration of the breath) was marginally greater when breathing orally (median $0.59,0.52-0.65$ ) than when breathing nasally $(0.57,0.53-0.60 ; \mathrm{p}=0.05)$.

The frequency of upper airway obstruction during sleep for all 12 subjects was profoundly influenced by the breathing route, being much greater during oral ventilation (apnoea-hypopnoea index 43 \pm 6 ) than nasal ventilation (apnoea-hypopnoea index $1.5 \pm 0.5, \mathrm{p}<0.0001)$. Despite the fact that subjects had more REM sleep during the nasal breathing condition, the apnoeahypopnoea index standardised for position (in the eight subjects who had position-comparable sleep periods in the two parts of the study) was still significantly greater in the oral breathing condition (supine position: nasal $3 \pm 2$, oral $31 \pm 8$; $\mathrm{p}=0.006$ (fig. 4); lateral position: nasal $2 \pm 1$, oral $29 \pm 9$; $\mathrm{p}=0.009$ (fig. 5)). Importantly, central sleep apnoea severity was not prevalent in either experimental condition, and did not differ between the oral $(2 \pm 1)$ and nasal $(0 \pm 1)$ breathing conditions $(\mathrm{p}=0.2)$.

Two subjects were excluded from analysis because the severity of obstructive sleep apnoea (OSA) in the oral breathing condition was so great that there was not enough stable sleep

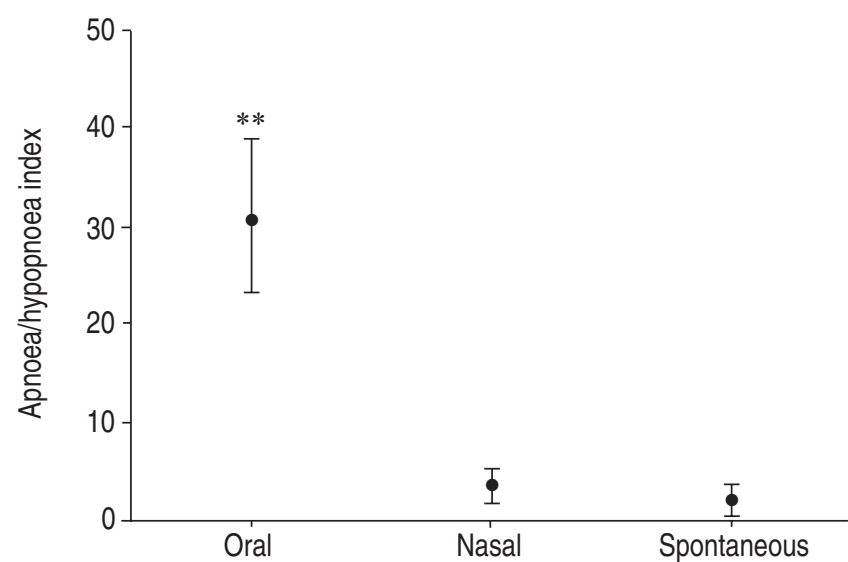

Fig. 4.-Effect of breathing route on sleep apnoea severity in the supine position. Data are presented as mean \pm SEM. ${ }^{* *}$ : $p<0.01$ oral versus nasal breathing route.

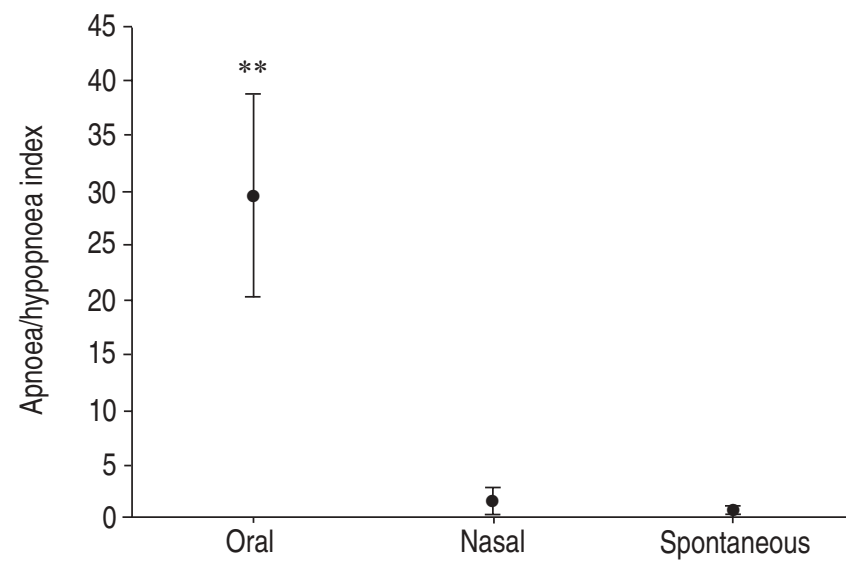

Fig. 5.-Effect of breathing route on sleep apnoea severity in the lateral position. Data are presented as mean \pm SEM. ${ }^{* *}: \mathrm{p}<0.01$ oral versus nasal breathing route.

free of obstructive events to permit a meaningful calculation of upper airway resistance.

After completion of data collection during the oral and nasal breathing conditions, each of the last six subjects studied was invited to return to sleep with both ports of the facemask open. Sleep was recorded for $89.6 \pm 11.5 \mathrm{~min}$ (55.5-130.5 min) in the latter condition. In five of the six cases no oral breathing could be detected during sleep, and in the remaining subject the oral fraction was detectable in only $25 \%$ of epochs of sleep, and remained $<5 \%$ of minute ventilation at all times. Hence, the nasal breathing condition in the study reflected the usual breathing route during sleep for these subjects.

\section{Discussion}

There are several novel aspects to these findings. First, the study documents, for the first time, a clearly increased upper airway resistance in association with oral breathing during stable sleep, as compared with nasal breathing, irrespective of central or OSA. Secondly, this methodology included simultaneous documentation of oral and nasal ventilation during sleep, to confirm the absence of any nasal airflow in the oral breathing condition and vice versa. Thirdly, this study demonstrates that, even in the absence of central apnoeas, the 
route of breathing has a profound influence on upper airway resistance during sleep, being much greater during oral breathing than nasal breathing. The substantially higher resistive load posed by the oral breathing route provides a plausible explanation for the observation that inhaled ventilation occurs almost exclusively via the nasal route during sleep in subjects with normal nasal resistance.

Why is resistance lower with nasal breathing as compared with oral breathing during sleep? Since reported measurements of total airway resistance are similar to that of nasal resistance alone during wakefulness, the well-documented preponderance of nasal ventilation while awake is an apparent paradox [9-11]. However, it is important to recognise that the reported measurements of airway resistance during wakefulness are obtained while the patient performs a panting manoeuvre (glottis open) through a mouthpiece, and do not reflect the normal configuration of the upper airway during quiet mouth breathing $[12,13]$. Indeed, it has already been well documented that the use of a mouthpiece renders markedly reduced values for airway resistance during wakefulness as compared with spontaneous mouth breathing without a mouthpiece [13]. More recently, AMIS et al. [12] have similarly demonstrated that upper airway resistance during mouth breathing in awake normal subjects is lower when breathing via a mouthpiece than when breathing through a facemask without a mouthpiece. In the latter study, the upper airway resistance values during mouth breathing without a mouthpiece were similar to the upper end of the normal range for nasal resistance. Hence, during relaxed normal awake respiration, there is no mechanical advantage to mouth breathing in the absence of nasal obstruction.

\section{Configurational changes in the upper airway with change in breathing route}

Fluoroscopic and computed tomography (CT) imaging studies have been conducted during wakefulness to examine the change in configuration of upper airway structures during nasal and oral breathing $[11,14]$. These studies concur in demonstrating a critical role for the soft palate in determining oral or nasal airflow. During mouth breathing, the soft palate was shown to move posteriorly against the posterior pharyngeal wall, thus closing the nasopharyngeal airway. During nasal breathing, the soft palate moved inferiorly and anteriorly until it lay against the dorsum of the tongue, thus closing the oropharyngeal airway. However, importantly, CT imaging (images taken at end inspiration and functional residual capacity in 30 supine normal subjects) did not demonstrate any compromise of the upper airway caliber at either retroglossal or hypopharyngeal levels during oral breathing as compared with nasal breathing and a compensatory increase in genioglossal EMG activity was documented in the oral breathing condition [14]. Imaging studies conducted during sleep in normal subjects and patients with OSA have demonstrated reductions in upper airway calibre at both retroglossal and retropalatal levels, with posterior and superior displacement of the tongue [15] but more marked narrowing at the retropalatal level $[16,17]$. No upper airway imaging studies have been performed during sleep to compare changes in upper airway configuration between oral and nasal breathing.

\section{Mouth opening}

Mouth opening has been documented during sleep in normal subjects and in patients with OSA [18, 19]. Mouth opening, even in the absence of oral airflow, has been shown to increase the propensity to upper airway collapse [20]. The two most likely explanations for the latter finding are that jaw opening is associated with a posterior movement of the angle of the jaw and compromise of the oropharyngeal airway diameter [21], and that posterior and inferior movement of the mandible may shorten the upper airway dilator muscles located between the mandible and hyoid and compromise their contractile force by producing unfavorable lengthtension relationships in these muscles [20]. The marked increase in upper airway resistance during sleep while mouth breathing in the current study, along with documentation during sleep in normal subjects of jaw opening, retroglossal airway patency, and a paucity of oral ventilation, might lead to speculatation that the most likely site of obstruction in the asleep normal subject breathing through the mouth may be the junction of the soft palate and tongue. However, the degree of jaw opening during sleep under conditions of forced breathing through the mouth in the current study is unknown and may be quite significant, and it has long been known that jaw opening can profoundly affect the diameter of the retroglossal airway [22]. Hence, it is plausible that the increased upper airway resistance observed in the current study during mouth breathing could be caused by compromise at both velopharyngeal and retroglossal levels.

\section{Control of the orallnasal breathing route}

Although the physiological mechanisms that govern oral and nasal distribution of ventilation have not been fully elucidated, some insights can be gleaned from the available literature. During exercise in normal subjects a progressive increase in the oral fraction of minute ventilation was observed with increasing workload, so that oral ventilation accounted for $>70 \%$ of the peak ventilation achieved [23]. The point at which the switch to oral ventilation was observed in the latter study corresponded to the onset of marked flow turbulence in the nasal airway. If the breathing route is fixed during awake hypercapnic challenge or exercise, then peak minute ventilation is reduced in the nasal breathing condition as compared with the oral breathing condition, and the difference in ventilation is closely correlated with the difference in resistance between the oral and nasal breathing routes [24]. In normal subjects at rest and awake, the change from pure nasal breathing to oronasal breathing occurs when an external inspiratory resistive load of $0.67 \mathrm{~Pa} \cdot \mathrm{cm}^{-3} \cdot \mathrm{s}^{-1}$ is added to the nasal breathing circuit, and the transition to pure oral breathing occurs at approximately twice that threshold load [25]. These findings suggest that nasal pressure receptors may be responsible for initiating the change in breathing route with increasing ventilation or added inspiratory resistive loads. However, resistive load perception was not different between the oral and nasal breathing routes [26], suggesting that similar pressure receptors are also present in the pharynx or more distal airways. In addition, although it was initially suggested that the nasal or oral breathing route might have differential effects on pharyngeal dilator muscle activation [27], subsequent work has refuted this finding (although activation of the alae nasae muscle was consistently greater during nasal breathing than oral breathing) [28, 29]. Hence, available evidence suggests that pressure receptors in the nose and other parts of the upper airway are responsible for sensing increasing resistance to nasal airflow, and initiating the switch to oronasal or oral breathing. Imaging studies suggest that this is achieved by activation of the muscles (palatoglossus and tensor palatini) controlling the position of the soft palate. Blockade of nasal mucosal receptors by topical application of local anaesthetic prolongs 
the latency of the switching response from nasal to oronasal breathing during wakefulness [30], and increases the propensity to upper airway obstruction during sleep [31]. However, it is not known whether blockade of nasal mucosal receptors alters the breathing route during sleep.

The current study also demonstrated a profound increase in OSA severity in the mouth breathing condition as compared with nasal breathing during sleep. No subject had any evidence of OSA during the nasal breathing condition, the normal pathway for ventilation during sleep. During wakefulness, nasal obstruction is associated with increased breathing through the mouth [9, 25], but there are no published measurements correlating nasal resistance with oral fraction during sleep. Nonetheless, there is other evidence that links nasal obstruction (whether or not it is associated with mouth breathing during sleep) with an increased tendency to sleep apnoea. A large epidemiological study demonstrated an increased prevalence of OSA among individuals with subjective nasal congestion due to allergy [32]. Similarly, a group of snorers with OSA were shown to have a higher nasal resistance than snorers without OSA [33].

Other studies have demonstrated an increased tendency to sleep apnoea during nasal occlusion in normal subjects, but did not measure mouth or nose breathing, or upper airway resistance, simultaneously [34-39]. This is relevant because, based on the findings of the current study, very severe nasal obstruction would be necessary to confer a mechanical advantage to the oral breathing route during sleep in normal subjects. Even the moderate nasal obstruction observed with allergic rhinitis that was associated with an increased prevalence of upper airway obstruction during sleep and reversed after the allergy season [39], would not be enough, based the authors current findings, to confer a mechanical advantage to pure mouth breathing during sleep. Hence, an increase in OSA severity in association with a moderate increase in nasal resistance may not necessarily indicate a switch to mouth breathing but could be caused by breathing through the "in series" nasal resistance rather than bypassing it. Furthermore, studies utilising artificial means to induce nasal occlusion demonstrated a marked increase in central sleep apnoea, which was sometimes the dominant finding [38], perhaps related to the irritant effect of the intranasal occlusion device, and central sleep apnoea may predispose to upper airway obstruction during sleep [40]. Hence, the relationship between nasal obstruction and OSA is well documented but nasal resistance per se appears not to be useful predictor for either the presence or absence of sleep apnoea, or for sleep apnoea severity [41-43]. Nonetheless, whether through the imposition of a resistance in series or a switch to mouth breathing during sleep, the findings of the current study suggest that normal subjects are likely to have significant OSA in the presence of severe nasal obstruction from any cause.

The findings of the current study would suggest a therapeutic role for improving the nasal airway in patients with nasal obstruction and OSA. However, published reports are inconsistent regarding the effects of attempts to improve nasal airway patency on sleep apnoea severity [39, 44-46]. The paucity of objective measurements of nasal resistance and of oral/nasal partitioning of ventilation before and after treatment of nasal obstruction in these studies hinders their interpretation. In addition, MEURICE et al. [20] have pointed out that patients with significant upper airway compromise at the retroglossal level (who may obstruct at that site independent of nasal obstruction) are less likely to respond to nasal surgery than those with a wider posterior airway space. Given the findings of the latter study and the profound effect of forced mouth breathing on OSA severity, it would be anticipated that selected patients with OSA, those with severe nasal obstruction and normal retroglossal airway dimensions, might demonstrate substantial improvement in sleep apnoea severity after relief of nasal obstruction, but this has not been evaluated in a prospective study.

In summary, upper airway resistance during sleep is significantly lower during nasal breathing than during oral breathing. In addition to increased upper airway resistance, the oral breathing route is associated with a marked increase in obstructive sleep apnoea severity, which is not related to coexistent central sleep apnoea. The disparity in upper airway resistance during sleep between nose and mouth breathing may contribute significantly to the predominance of nasal breathing during sleep in healthy adults.

\section{References}

1. Fitzpatrick MF, Driver HS, Chatha N, Voduc N, Girard AM. Partitioning of inhaled ventilation between the nasal and oral routes during sleep in normal subjects. J Appl Physiol 2003; 94: 883-890.

2. Rossi A, Polese G, Milic-Emili J. Monitoring respiratory mechanics in ventilator dependent patients. In: Tobin MJ, ed. Principles and practice of intensive care monitoring. New York, McGraw-Hill Inc., 1998; pp. 553-596.

3. Gleeson K, Zwillich CW, Braier K, White DP. Breathing route during sleep. Am Rev Respir Dis 1986; 134: 115-120.

4. American Academy of Sleep Medicine Task Force. Sleeprelated breathing disorders in adults: recommendations for syndrome definition and measurement techniques in clinical research. Sleep 1999; 22: 667-689.

5. Spann RW, Hyatt RE. Factors affecting upper airway resistance in conscious man. J Appl Physiol 1971; 31: 708712.

6. Liistro G, Stanescu D, Dooms G, Rodenstein D, Veriter C. Head position modifies upper airway resistance in men. J Appl Physiol 1988; 64: 1285-1288.

7. Choi JK, Goldman M, Koyal S, Clark G. Effect of jaw and head position on airway resistance in obstructive sleep apnoea. Sleep Breath 2000; 4: 163-168.

8. Hudgel DW, Robertson DW. Nasal resistance during wakefulness and sleep in normal man. Acta Otolaryngol 1984; 98: 130-135.

9. Lieberman A, Ohki M, Forte V, Fraschetti J, Cole P. Nose/ mouth distribution of respiratory airflow in "mouth breathing" children. Acta Otolaryngol 1990; 109: 454460.

10. Niinimaa V, Cole P, Mintz S, Shephard RJ. The switching point from nasal to oronasal breathing. Respir Physiol 1980; 42: 61-71.

11. Rodenstein DO, Stanescu DC. Soft palate and oronasal breathing in humans. $J$ Appl Physiol 1984; 57: 651-657.

12. Amis TC, $\mathrm{O}^{\prime}$ Neill $\mathrm{N}$, Wheatley JR. Oral airway flow dynamics in healthy humans. J Physiol 1999; 515: 293-298.

13. Cole P, Forsyth R, Haight JSJ. Respiratory resistance of the oral airway. Am Rev Respir Dis 1982; 125: 363-365.

14. Burger CD, Stanson AW, Daniels BK, Sheedy PF, Shepard JW. Fast-computed tomographic evaluation of the effect of route of breathing on upper airway size and function in normal men. Chest 1993; 103: 1032-1077.

15. Horner RL, Shea SA, McIvor J, Guz A. Pharyngeal size and shape during wakefulness and sleep in patients with obstructive sleep apnoea. $Q J$ Med 1989; 72: 719-735.

16. Trudo FJ, Gefter WB, Welch KC, Gupta KB, Maislin G, Schwab RJ. State-related changes in upper airway caliber and surrounding soft-tissue structures in normal subjects. Am J Respir Crit Care Med 1998; 158: 1259-1270.

17. Stein MG, Gamsu G, de Geer G, Golden JA, Crumley RL, Webb WR. Cine CT in obstructive sleep apnoea. Am J Roentgenol 1987; 148: 1069-1074.

18. Hollowell DE, Suratt PM. Mandible position and activation of submental and masseter muscles during sleep. $J$ Appl Physiol 1991; 71: 2267-2273. 
19. Miyamoto K, Ozbek MM, Lowe AA, et al. Mandibular posture during sleep in healthy adults. Arch Oral Biol 1998; 43: 269-275.

20. Meurice J-C, Marc I, Carrier G, Series F. Effect of mouth opening on upper airway collapsibility in normal sleeping subjects. Am J Respir Crit Care Med 1996; 153: 255-259.

21. Kuna ST, Remmers JE. Neural and anatomic factors related to upper airway occlusion during sleep. Med Clin North Am 1985; 69: 1221-1242.

22. Morikowa S, Safer P, Decarlo J. Influence of the head-jaw position upon upper airway patency. Anaesthesiology 1961; 22: $265-270$

23. Fregosi RF, Lansing RW. Neural drive to nasal dilator muscles: influence of exercise intensity and oronasal flow partitioning. J Appl Physiol 1995; 79: 1330-1337.

24. Shi YX, Seto-Poon M, Wheatley JR. The breathing route dependence of ventilatory responses to hypercapnia and exercise is modulated by upper airway resistance. Respirology 1999; 4: 331-338.

25. Ohki M, Usui N, Kanazawa H, Hara I, Kawano K. Relationship between oral breathing and nasal obstruction in patients with obstructive sleep apnoea. Acta Laryngol 1996; 523: 228-230.

26. Gleeson K, Bendrick T, White DP. Role of the nose in resistive load detection. J Appl Physiol 1986; 61: 1908-1913.

27. Basner RC, Simon PM, Schwartzstein RM, Weinberger SE, Weiss JW. Breathing route influences upper airway muscle activity in awake normal adults. J Appl Physiol 1989; 66: 1766-1771.

28. Shi YX, Seto-Poon M, Wheatley JR. Breathing route dependence of upper airway muscle activity durign hyperpnea. J Appl Physiol 1998; 84: 1701-1706.

29. Williams JS, Janssen PL, Fuller DD, Fregosi RF. Influence of posture and breathing route on neural drive to upper airway dilator muscles during exercise. J Appl Physiol 2000; 89: $590-598$

30. Nishino T, Sugiyama A, Tanaka A, Ishikawa T. Effects of topical nasal anesthesia on shift of breathing route in adults. Lancet 1992; 339: 1497-1500.

31. White DP, Cadieux RJ, Lombard RM, Bixler EO, Kales A, Zwillich CW. The effects of nasal anesthesia on breathing during sleep. Am Rev Respir Dis 1985; 132: 972-975.

32. Young T, Finn L, Kim H. Nasal obstruction as a risk factor for sleep-disordered breathing. J Allergy Clin Immunol 1997; 99: 757-762.

33. Lofaso F, Coste A, d'Ortho MP, et al. Nasal obstruction as a risk factor for sleep apnoea syndrome. Eur Respir J 2000; 16: 639-643.

34. Lavie P, Fischel N, Zomer J, Eliaschar I. The effects of partial and complete mechanical obstruction of the nasal passages on sleep structure and breathing in sleep. Acta Otolaryngol 1983; 95: 161-166.

35. Carskadon MA, Bearpark HM, Sharkey KM, et al. Effects of menopause and nasal occlusion on breathing during sleep. Am J Respir Crit Care Med 1997; 155: 205-210.

36. Olsen KD, Kern EB, Westbrook PR. Sleep and breathing disturbance secondary to nasal obstruction. Otolaryngol Head Neck Surg 1981; 89: 804-810.

37. Suratt PM, Turner BL, Wilhoit SC. Effect of intranasal obstruction on breathing during sleep. Chest 1986; 90: 324 329.

38. Zwillich CW, Pickett C, Hanson FN, Weil JV. Disturbed sleep and prolonged apnoea during nasal obstruction in normal men. Am Rev Respir Dis 1981; 124: 158-160.

39. McNicholas WT, Tarlo S, Cole P, Zamel N, Rutherford R, Griffin D. Obstructive apnoeas during sleep in patients with seasonal allergic rhinitis. Am Rev Respir Dis 1982; 126: 625628.

40. Badr MS, Toiber F, Skatrud JB, Dempsey J. Pharyngeal narrowing/occlusion during central sleep apnoea. $J$ Appl Physiol 1995; 78: 1806-1815.

41. Metes A, Ohki M, Cole P, Haight JS, Hoffstein V. Snoring, apnoea and nasal resistance in men and women. $J$ Otolaryngol 1991; 20: 57-61.

42. Miljeteig H, Robertson DW. Nasal resistance in recumbency and sleep. Rhinology 1995; 33: 82-83.

43. Miljeteig H, Savard P, Mateika S, Cole P, Haight JS, Hoffstein V. Snoring and nasal resistance during sleep. Laryngoscope 1993; 103: 918-923.

44. Bahammam AS, Tate R, Manfreda J, Kryger MH. Upper airway resistance syndrome: effect of nasal dilation, sleep stage, and sleep position. Sleep 1999; 22: 592-598.

45. Dayal VS, Phillipson EA. Nasal surgery in the management of sleep apnoea. Ann Otol Rhinol Laryngol 1985; 94: 550-554.

46. Irvine BW, Dayal VS, Phillipson EA. Sleep apnoea due to nasal valve obstruction. J Otolaryngol 1984; 13: 37-38. 